\section{La Enfermedad de Carrión: la teoría unicista y el aporte de los campesinos}

\section{Carrión's disease: the role of popular medicine in a unifying theory}

"No debe avergonzarnos de tomar del pueblo todo aquello que puede ser útil en el arte de curar"

Hipócrates. Siglo IV a.C.

\section{Sr. Editor:}

La enfermedad de Carrión es una infección que se ha reportado sólo en Perú, Colombia y Ecuador. Es la enfermedad más investigada en toda la historia de la medicina peruana. Presenta dos fases clínicas: una conocida como "Fiebre de la Oroya", caracterizada por fiebre y anemia severa de tipo hemolítico, y una fase tardía, en la que el paciente desarrolla erupciones dermatológicas conocida como "verruga peruana". El sentido común hace pensar que, por ser tan disímiles, la Fiebre de la Oroya y la verruga peruana serían dos enfermedades diferentes; sin embargo, se ha demostrado que estas dos formas clínicas forman parte de una misma enfermedad, concepto que es denominado la teoría unicista de la Enfermedad de Carrión. Varios estudios históricos han resaltado el papel de los científicos en la construcción de esta teoría, sin embargo, ha pasado desapercibido que la primera evidencia documentada de esta teoría unicista, proviene de los campesinos peruanos, de la medicina tradicional (Figura 1).

En 1764, Cosme Bueno, médico aragonés, en su libro "El Conocimiento de los Tiempos" documentó el conocimiento de la medicina tradicional sobre la verruga peruana, que existía en la provincia de Canta: ${ }^{1}$

"Las quebradas son muy enfermizas, en que se notan dos males... uno es de berrugas, que en no brotando a tiempo suele ser enfermedad bien molesta y peligrosa".

Cuando los indígenas llaman a esta enfermedad "molesta y peligrosa", se interpreta que se refieren a la mortalidad de la fase inicial febril anemizante.

Cosme Bueno fue catedrático de la Universidad Nacional Mayor de San Marcos, y sería años después preceptor del sabio Hipólito Unánue. Bueno, además de médico, era profesor de matemáticas y Cosmógrafo Mayor del Virreinato del Perú, editó durante décadas "El Conocimiento de los Tiem- pos", un anuario que describía los lugares geográficos del virreinato del Perú. Los cosmógrafos eran eruditos descriptores de toda la información cultural de un determinado territorio.

Durante el resto del período virreinal, hubo escasos registros que documentaron la enfermedad de Carrión. Entre ellos figuran los del cirujano Gago de Vadillo, de Martín Delgar, y el sabio Hipólito Unánue, pero no hicieron mención a la teoría unicista.

En 1777, el botánico Hipólito Ruiz² fue enviado por el Rey de España a una expedición de siete años a Perú y Chile, para obtener la "cinchona", especie botánica que produce la quinina, otro aporte de la medicina tradicional peruana. Ruíz documentó en sus escritos el conocimiento tradicional desarrollado en Canta, relacionado a las dos fases de la enfermedad de Carrión:

"En algunas quebradas, la enfermedad llamada verrugas es común y no erupciona rápidamente, es continuación de una larga y algunas veces problemática enfermedad".

En 1793, Tadeo Haenke, relató también conocimientos folklóricos relacionados con las dos fases de la verruga, en Canta ${ }^{3}$.

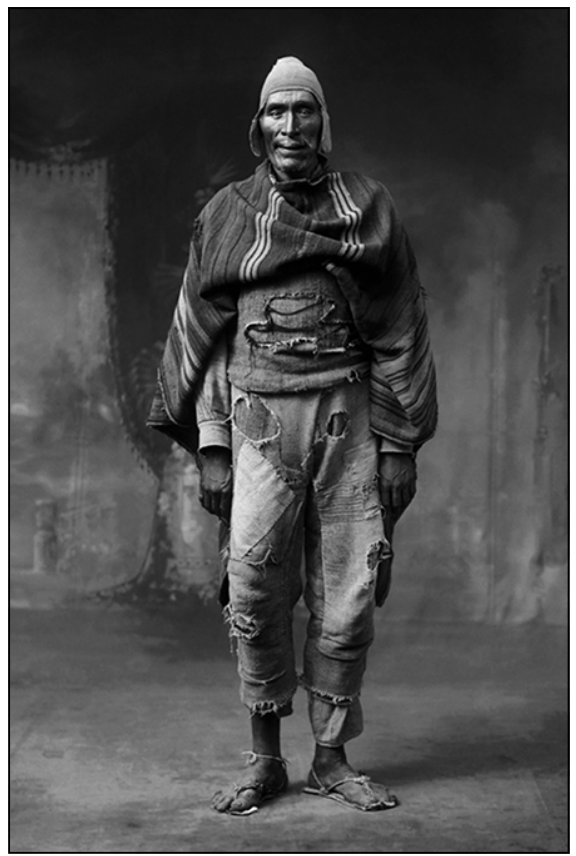

Figura 1. Campesino peruano. La primera evidencia de la teoría unicista fue obtenida por los campesinos. Fuente: Campesino cusqueño Juan de la Cruz de Chumbivilcas 1927 (Foto Archivo fotográfico de Martín Chambi, Cuzco Perú / www. martinchambi.org). 
En 1858, Johan Jacob Von Tschudi ${ }^{3}$, un viajero sueco peruanista, documentó en sus escritos sobre sus viajes, el conocimiento popular que insinuaba la teoría unicista, expresando:

"Si la aparición de la verruga se tarda, pone en gran peligro al paciente".

Según algunos autores del Mercurio Peruano, varios académicos copiaron la obra de Cosme Bueno, sin mencionarlo como autor, por lo que sus conocimientos lograron trascender posiblemente durante toda la colonia.

Los aportes de los viajeros peruanistas como Ruiz, Haenke, Tschudi, documentaron también el conocimiento folklórico sobre la teoría unicista, pero probablemente no fue considerado por la comunidad médica peruana, porque los viajeros no eran médicos.

En 1871, durante la construcción del ferrocarril Trasandino Lima-La Oroya, se desarrolló una mortal epidemia de fiebre con anemia severa, que le llamaron "Fiebre de la Oroya". Ricardo Espinal, médico venezolano radicado en Perú, observó pacientes con Fiebre de la Oroya que sobrevivían y desarrollaban la verruga peruana. Obtuvo así evidencia clínica observacional, de la teoría unicista. En una sesión médica, el médico Kiney, respaldó la teoría unicista de Espinal, porque concordaba con los conocimientos de la medicina tradicional ${ }^{4}$.

"Es una creencia vulgar que la fiebre depende de la verruga que no ha salido y que para sanar de ellas es indispensable hacerlas brotar sobre la piel"

En 1885, el estudiante de medicina Daniel Alcides Carrión, realizó su histórico experimento, autoinoculándose secreciones de un paciente con verruga peruana desarrollando probablemente Fiebre de la Oroya, y brindó la evidencia clínica experimental de la teoría unicista. Los hallazgos de la medicina tradicional, del Dr. Espinal, de Carrión y de la epidemiologia de la enfermedad, llevaron a una inicial consolidación de la teoría unicista.

En 1913, una expedición de la universidad de Harvard liderada por Richard Strong, concluyó erróneamente que la Fiebre de la Oroya y la verruga peruana son dos enfermedades diferentes. Sin embargo, sus conclusiones no explicaban la clínica y la epidemiología de esta enfermedad.

En 1926, Hideyo Noguchi logró aislar la Bartonella bacilliformis en las dos formas clínicas de la enfermedad, realizando la demostración bacteriológica de la teoría unicista. Pese a ello, en 1930, científicos franceses del Instituto Pasteur, liderados por André Lwoff, futuro Premio Nobel de Medicina $^{5}$, interpretaron erróneamente los hallazgos de Noguchi, e intentaron revivir la teoría dualista. La Academia Nacional de Medicina de Perú, en respuesta, emitió una declaración conjunta defendiendo la teoría unicista. Los posteriores avances en microscopia electrónica y en bioquímica han documentado plenamente esta teoría.

La teoría unicista, adelantándose a su época, implícitamente también reveló el hecho de que un mismo agente infeccioso puede producir dos cuadros nosológicos diferentes, como sucede con el virus herpes, que produce la varicela y el herpes zoster.

Aunque se difunde el concepto que las innovaciones científicas teóricas dependen de grandes científicos $^{6}$, es poco resaltado que este aporte científico también proviene de la medicina popular. Este es el caso de la teoría unicista de la enfermedad de Carrión.

\section{David Salinas Flores \\ Profesor Invitado, Cátedra Medicina}

Humana. Universidad Nacional Mayor de San Marcos y Hospital Arzobispo Loayza. Lima, Perú.

\section{Referencias}

1. Bueno C. El Conocimiento de los tiempos. Lima. Imprenta Oficina de la calle Coca, 1764.

2. Ruiz H. Travels of Ruiz, Pavón and Dombey in Peru and Chile (1777-1788). Botanical Series, Field Museum of Natural History, Chicago. Vol 21. 372 pgs. 1940.

3 Herrer A. Epidemiología de la verruga peruana. $1^{\text {a }}$ Edición. Lima Perú. Edit. Gonzáles Mundaburu 120 pgs. 1990.

4 Sesión del 3 de septiembre de la Sociedad Médica. La Gaceta Médica 1875; 1 (21): 165-6.

5 Soyer-Gobillard MO, Schrevel J. André Lwoff (19021994), Nobel Prize of Medicine, as protistologist. Protist 2003; 154 (3-4): 455-68.

6 Hawkins S. A Hombros de Gigantes: Las Grandes Obras de la Física y la Astronomía. Barcelona, España. $1^{\text {a }}$ ed. Crítica SL. 1032 pgs. 2010.

Conflictos de intereses: ninguno que declarar.

Correspondencia a:

David Salinas Flores.

Federico Villarreal 592, Urbanización Ingeniería, Distrito San

Martin de Porres. Lima, Perú.

dsalinas2009@yahoo.com 